Original Article

\title{
IMPURITY PROFILING OF FIRST LINE ANTI-TB DRUG-TERIZIDONE USING CHROMATOGRAPHIC AND RELATED TECHNIQUES
}

\author{
PRAGATI J. VANAVI, SADHANA J. RAJPUT* \\ Faculty of Pharmacy, Shree G H Patel Center for Relevance and NDDS, Vadodara, Gujarat India 390002, The Maharaja Sayajirao University \\ of Baroda \\ "Email: sjrajput@gmail.com \\ Received: 29 Jan 2021, Revised and Accepted: 02 Apr 2021
}

ABSTRACT

Objective: The objective of the present study was to investigate the stability of TRZ against different stressors and to prepare impurity profile for potential impurities and degradation products (DPs) formed under stress degradation of TRZ bulk drug and formulation.

Methods: Three analytical methods were developed; the stability-indicating method that was developed using HPLC instrument with $0.01 \mathrm{M}$ ammonium acetate buffer ( $\mathrm{pH} 4.0$ using glacial acetic acid (GAA)) and acetonitrile in gradient program. The second method was a UPLC/ESI-MS method using $0.1 \%$ Formic acid in Milli $\mathrm{Q}$ water $(\mathrm{pH}=2.70)$ and $0.1 \%$ Formic acid in Milli $\mathrm{Q}$ water: Acetonitrile $(10: 90)$ in gradient program for identification of TRZ and DPs while the third, preparative HPLC method was used for isolation of impurities using $(\mathrm{A}) 0.05 \% \mathrm{ammonia}\left(\mathrm{NH}_{3}\right)$ in water and (B) Acetonitrile $+20 \%$ mobile phase A in gradient sequence. Gradient sequences are described in the main text.

Results: The analytical method for stability study was developed and validated using ICH (Q2) R1 guidelines. The result of stability study by stress degradation showed that TRZ was susceptible to degradation in acid (7 DPs), alkaline, neutral (9 DPs) and oxidative conditions (10 DPs); major DPs were identified (where it was possible) and the chemical structure was elucidated by combining the data of ESI/MS, NMR and/or Tandem MS. The Impurity profiling was completed by reporting all the DPs, either major or minor for TRZ bulk drug and formulation.

Conclusion: The complete Impurity profiling for TRZ is reported for the first time in literature. The study data would be add-on for formulation storage condition and further development.

Keywords: HPLC, Impurity study, LC-MS, NMR, Stability study, Terizidone

(C) 2021 The Authors. Published by Innovare Academic Sciences Pvt Ltd. This is an open access article under the CC BY license (https://creativecommons.org/licenses/by/4.0/) DOI: https://dx.doi.org/10.22159/ijpps.2021v13i5.40918. Journal homepage: https://innovareacademics.in/journals/index.php/ijpps.

\section{INTRODUCTION}

Research of novel therapeutic treatment for TB cure is the interesting and challenging topic for researchers since the TB bacteria $M$. tuberculosis was identified by Dr. Robert Koch in 1882 [1]. The reports show that in 2019 third-highest HIV negative TB death mortality was observed in India. All over world, 1.2 million people died due to TB infections (HIV positive and negative) [2]. It shows that survival pattern of bacteria are developed against the antibiotics in human body, therefore, bacteria are resistant to certain antibiotics and remains ineffective by those anti-TB drugs; therefore microbiologist and researchers are still working on century-old disease and bacteria. Terizidone was approved by CDSCO (Central drugs standard control organization) of India in 1981 for treatment of TB, which is synthesized by combining two molecules of D-Cycloserin using a benzene ring. The chemical structure of TRZ is shown in fig. 1. (A and $B$ refers to the D-cycloserin rings)TRZ is indicated in MDR-TB (Multidrug resistance TB) [3].

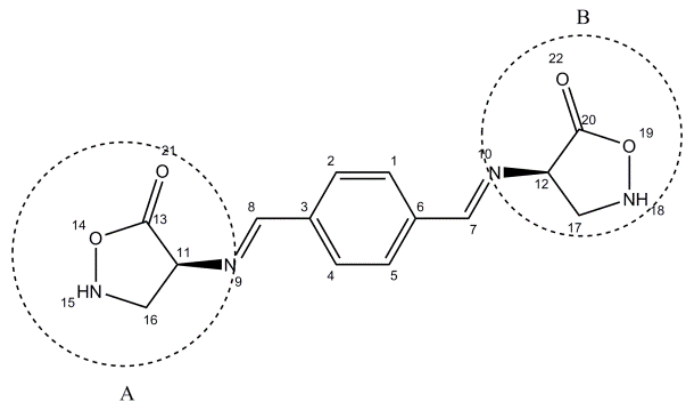

Fig. 1: Chemical structure of Terizidone
The extensive literature survey shows several reported methods which are; UV method [4], HPLC method for TRZ in plasma [5], stability study for TRZ [6] (degradation products were not separated nor reported), the two degradation products of TRZ are reported by HPTLC and MS/MS method [7] (the DPs are marked with an asterisk in paper and cited which are reported in literature), HPTLC and LC/MS/MS methods are reported [8]. None of the reported literature investigates the entire impurity profile for TRZ, therefore it was an opportunity and challenge to study stress degradation and report the impurity profile of TRZ. In this study, the novel DPs and process-related impurities are extensively studied and reported in the literature for the first time. The objective of the study was to study stress degradation and prepare an impurity profile of TRZ.

\section{MATERIALS AND METHODS}

\section{Chemicals and reagents}

TRZ bulk drug was obtained as a gift sample from Macleods Pharma Pvt. Ltd. (Gujarat, India). HPLC grade methanol and acetonitrile was purchased from Rankem Chemicals, Gurugram, India. Ammonium acetate buffer was purchased from Loba Chemicals Pvt. Ltd, Mumbai, India. Glacial acetic acid ( $>99.0 \%$ purity), ammonia and NMR grade deuterated Di-Methyl Sulph Oxide (DMSO) were procured from Sigma-Aldrich (USA). UPLC/ESI-MS (Ultra Performance Liquid Chromatography/Electron Spray Ionization-Mass Spectrometer) grade acetonitrile was purchased from Fisher Scientific chemicals, India. Formic acid was purchased from Merck, USA. Analytical grade hydrochloric acid $(\mathrm{HCl})$ and sodium hydroxide $(\mathrm{NaOH})$ were procured from SD Fine Chem. Ltd., Mumbai. Hydrogen peroxide $\left(\mathrm{H}_{2} \mathrm{O}_{2}\right)$ was procured from Fischer Ltd., India. The water for studies was prepared by deionization of water in the laboratory.

Unless and otherwise specified, all solutions were filtered through a $0.45 \mu \mathrm{m}$ Nylon 6,6 membrane filter, Ultipore ${ }^{\circledR}$ N66 $®$ From Pall Life Sciences, USA; prior to use. 


\section{UV spectrophotometer}

The suitable wavelengths for estimation of API were identified by scanning over the range of 200-400 $\mathrm{nm}$ with a Shimadzu UV-1700 double beam Spectrophotometer (Shimadzu, Japan), which contains double beam optics with scanning range 190-800 $\mathrm{nm}$ with maximum stray light of $0.04 \%$ and wavelength accuracy $\pm 0.3 \mathrm{~nm}$, spectral band width was $1 \mathrm{~nm}$, scanning speed approx. $3000 \mathrm{~nm} / \mathrm{min}$ with silicone photodiode detector.

\section{Liquid chromatographic system}

The HPLC (High-Performance Liquid Chromatographic) system consisted of manual injector, low pressure gradient flow control valve, solvent delivery module, photodiode array(PDA) detector, and system controller with Empower-2 Software (all from Waters Acquity Corporation, Milford, MA, USA). For method development, the separation was accomplished on a Thermo scientific RP-C ${ }_{18}$ column $(250 \times 4.6 \mathrm{~mm}, 5 \mu \mathrm{m})$ at wavelength $270 \mathrm{~nm}$. The analysis was performed at ambient temperature with manual sample loading of $20 \mu \mathrm{l}$. The mobile phase was filtered through $0.22 \mu \mathrm{m}$ disposable filters (Ultipore $\AA$, PALL Life sciences, USA), and degassed with provisional ultra sonicator prior to use.

\section{Method}

Stability indicating method was developed to achieve maximum possible separation between degradation products and TRZ bulk drug-using A) $0.01 \mathrm{M}$ ammonium acetate buffer $\mathrm{pH} 4.7$ with glacial acetic acid and B) acetonitrile as mobile phase ran in gradient mode. The gradient Program used for the separation is shown as time (min.)/\% A; 0/95, 10/95, 50/70, 55/95, 60/95, flow rate was 1 $\mathrm{ml} / \mathrm{min}$.

\section{UPLC-MS}

Study was completed on Waters Acquity UPLC with quaternary solvent manager with PDA detector, column oven, Acquity ESI performance mass detector and autosampler. Mass analysis was carried out on single quad mass spectrometer equipped with Waters jet stream Electron Spray Ionization (ESI) source with positive mode (Waters corp. USA). Mass Lynx software was used for the UPLC-PDA and UPLC/ESI-MS data acquisition and analysis of TRZ and its DP.

UPLC/ESI-MS study was carried out using mobile phase a) $0.1 \%$ formic acid in Milli $\mathrm{Q}$ water $(\mathrm{pH}=2.70)$ and $\mathrm{b}) 0.1 \%$ formic acid in Milli Q water: acetonitrile (10:90). Gradient elution program was set to $\mathrm{T} /(\% \mathrm{~A})=0 \mathrm{~min}(97 \%)$ flow: $0.8 \mathrm{ml} / \mathrm{min} ; 0.75 \mathrm{~min}(97 \%) ; 2.7 \mathrm{~min}$ (2\%); $3 \mathrm{~min}(0 \%) ; 3.5 \mathrm{~min}(0 \%) ; 3.51 \mathrm{~min}(97 \%)$; end of run at 4 $\min (97 \%)$, Flow rate: $1 \mathrm{ml} / \mathrm{min}$, analysis time $4 \mathrm{~min}$.

Mass probe (Probe temperature $400{ }^{\circ} \mathrm{C}$ ) was set as source for electrospray ionization in positive mode (temp. $120{ }^{\circ} \mathrm{C}$ ) with cone voltage 10 and $30 \mathrm{~V}$ and capillary voltage $3.25 \mathrm{kV}$. Cone gas flow and desolvation $\left(400{ }^{\circ} \mathrm{C}\right)$ gas flow was 100 and $800 \mathrm{~L} / \mathrm{hr}$, respectively. Column and autosampler temperature was set to $35^{\circ}$ and $5{ }^{\circ} \mathrm{C}$, respectively.

\section{Preparative HPLC}

The major acid stress degradation was isolated using preparative HPLC: Waters 2489 binary, autosampler and auto fraction collector, high pressure mixing chamber, and UV detector. Rheodyne injector was used to load a sample in chromatographic system.

The major acid stress degradation product was isolated using stationary phase YMC Actus Triart $\left(C_{18}, 250 \times 20 \mathrm{~mm}, 5 \mu\right)$ column set to ambient temperature. Mobile phase consisted of a) $0.05 \%$ ammonia $\left(\mathrm{NH}_{3}\right)$ in water and b) acetonitrile $+20 \%$ mobile phase $\mathrm{A}$ with flow rate $18.0 \mathrm{ml} / \mathrm{min}$, PDA detection at $270 \mathrm{~nm}$. Gradient elution program was set as follows; run time $23 \mathrm{~min}$; $\mathrm{T}(\mathrm{min})=\% \mathrm{v} / \mathrm{v}$ A: $0.01(100 \%), 2$ (100\%),17.0 (90\%),17.01 (2\%), 20 (2\%), 20.1 $(100 \%)$ and stop command after $23 \mathrm{~min}(100 \%)$.

MS/MS data were obtained on system (Thermoscientific, USA) with MS plus pump and autosampler. TSQ Quantum access max mass spectrometer was used for analysis. The MS system used spray electron ionization in positive mode with voltage 3500V, Capillary temperature was $300{ }^{\circ} \mathrm{C}$. The Mass transition was observed for M1 and M2 level with collision energy $34 \mathrm{eV}$ for both transition. Xcalibur Software was used for data analysis (Thermo Fisher, USA).

NMR: NMR was performed on Bruker $400 \mathrm{MHz}$ NMR spectrometer using deuterated dimethyl sulphoxide (DMSO-d6) and $\mathrm{D}_{2} \mathrm{O}$ (deuterated water) as solvent. Chemical shifts were recorded in ppm ( $\delta$ Scale) and coupling constants in Hertz against TMS $(0 \delta$ ppm) as an internal standard. For data analysis Top spin software 3.2 was used.

Precision Water/Oil bath (EIE, India) with temperature controller equipment was used for stress degradation studies to maintain temperature of samples.

Photolytic degradation study was carried out in a photostability chamber (Thermolab Scientific Equipments Pvt Ltd, Vadodara) Equipped with a light back consisting of four UV (OSRAM L73) and Fluorescent (OSRAM L20) lamps, that complied with specifications prescribed in the ICH guideline Q1B. The system is capable of controlling specific temperature and humidity $\left( \pm 2{ }^{\circ} \mathrm{C}\right.$ and $\left.\pm 5 \% \mathrm{RH}\right)$.

Other equipments used were an Ultrasonic bath (Analab Scientific Instruments Pvt Ltd, Vadodara), Precision analytical balance (AX 120, by Shimadzu Corporation analytical and measuring instruments division, Kyoto, Japan.), pH Meter (Lab India Instruments Pvt Ltd., Navi Mumbai). The analysis of data and Calculations were done using Microsoft Excel-2007.

\section{Sample preparation}

TRZ (accurately weighed $500 \mathrm{mg}$ ) was dissolved in $3 \mathrm{ml}$ DMSO and sonicated for $15 \mathrm{~min}$ with provisional shaking; $50 \mathrm{ml}$ final volume was achieved using $6 \%$ hydrogen peroxide, $0.5 \mathrm{~N} \mathrm{HCl}, 0.5 \mathrm{~N} \mathrm{NaOH}$ and water (final concentration $100 \mathrm{mg} / \mathrm{ml}$ ) individually. At regular time interval aliquot of $2 \mathrm{ml}$ was withdrawn from the 0 minute to till the degradation in TRZ was observed, the sample was kept in dark and diluted to $10 \mathrm{ml}$ with methanol $(20 \mathrm{mg} / \mathrm{ml})$, filtered through $0.45 \mu$ Pall syringe filter and injected in chromatographic system described in section materials and methods in RP-HPLC for data acquisition and analytical purpose.

TRZ was stressed under different conditions so that $5-100 \%$ decreases in peak area of TRZ bulk drug could be noticed. Marketed formulation of TRZ (Tericox, Macleods Pharma Pvt. Ltd.) was treated similar degradation conditions as performed for bulk drug-using tablet powder equivalent to $10 \mathrm{mg}$ of TRZ to determine the formation of any DPs due to drug-excipient, drug-stressor or stressor-excipient interaction.

\section{Stress degradation study}

The stress degradation of TRZ was investigated under hydrolytic solutions (acid, alkali and water), in oxidative medium, under thermal condition and photolytic condition. TRZ degraded significantly in hydrolytic solutions (acid and water) and oxidative solution while it remains stable in thermal and photolytic conditions. There was no major DP in alkaline conditions; instead, several fractions of TRZ were obtained, shown in fig. 2 (D), and therefore no DPs are reported. The results for stress degradation study are shown in table 1.

\section{Isolation of DPs}

The major DP was identified by the maximum \% area covered by the DP peak in HPLC chromatogram with peak purity. The degradation impurity was isolated using preparative HPLC; instrumental and chromatographic specifications are described in section materials and methods.

High concentration sample was prepared for isolation: accurately weighed $5 \mathrm{gm}$ of TRZ was dissolved separately in $15 \mathrm{ml}$ methanol with provisional shaking for 15 minutes by sonication; $50 \mathrm{ml}$ final volume was achieved using $0.5 \mathrm{~N} \mathrm{HCl}$, water and $6 \% \mathrm{H}_{2} \mathrm{O}_{2}$, the solution was kept in specified stability conditions in the dark $(0.5 \mathrm{~N}$ $\mathrm{HCl}$ at RT for $24 \mathrm{~h}$, water at RT for $24 \mathrm{~h}$ and $6 \% \mathrm{H}_{2} \mathrm{O}_{2}$ at RT for $5 \mathrm{~h}$ ). Aliquot of $2.6 \mathrm{ml}$ sample load $(0.6 \mathrm{ml}$ vial+1 $\mathrm{ml}$ water+1 $\mathrm{ml}$ methanol) was injected in described chromatographic condition of preparative HPLC. The fractions were collected separately and combined to concentrate the fraction by removing organic solvent 
on rotavapor and washing with water to remove the buffer used in the mobile phase. The concentrated sample was again injected in system to check against purity and for other co-eluting substance presence. The concentrated sample was freeze-dried to get a solid after confirmation of purity $>98.0 \%$ by HPLC. This final product was analyzed for LC/ESI-MS and NMR $\left({ }^{1} \mathrm{H},{ }^{13} \mathrm{C}\right.$ and APT (Attached proton Test)) or MS/MS.

\section{RESULTS}

Degradation behavior of TRZ

TRZ undergoes degradation in hydrolytic solution and in the presence of an oxidative agent. The process-related impurity was observed with bulk drug chromatogram, the chromatograms separating DPs and TRZ in different conditions are shown in fig. 2.

A
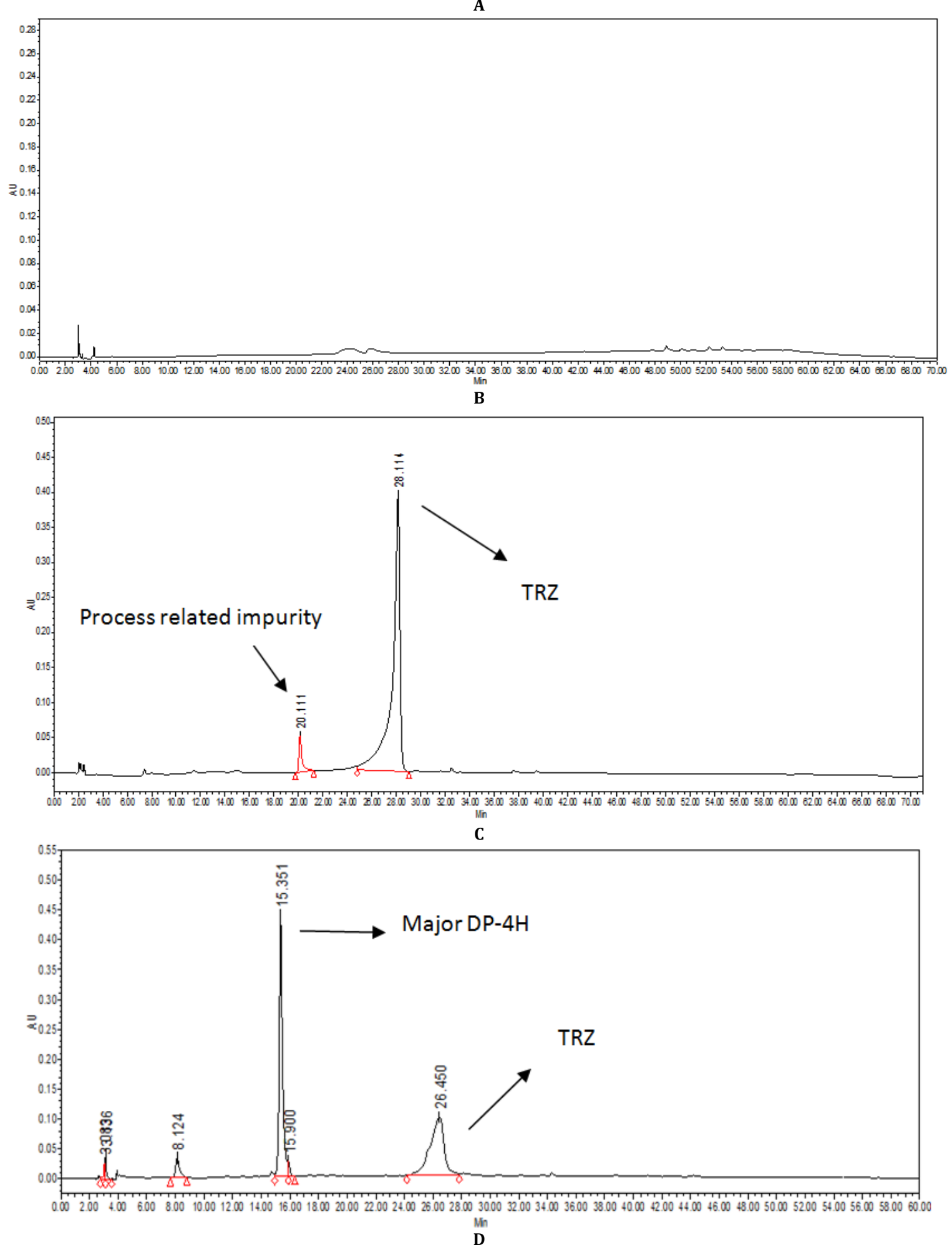

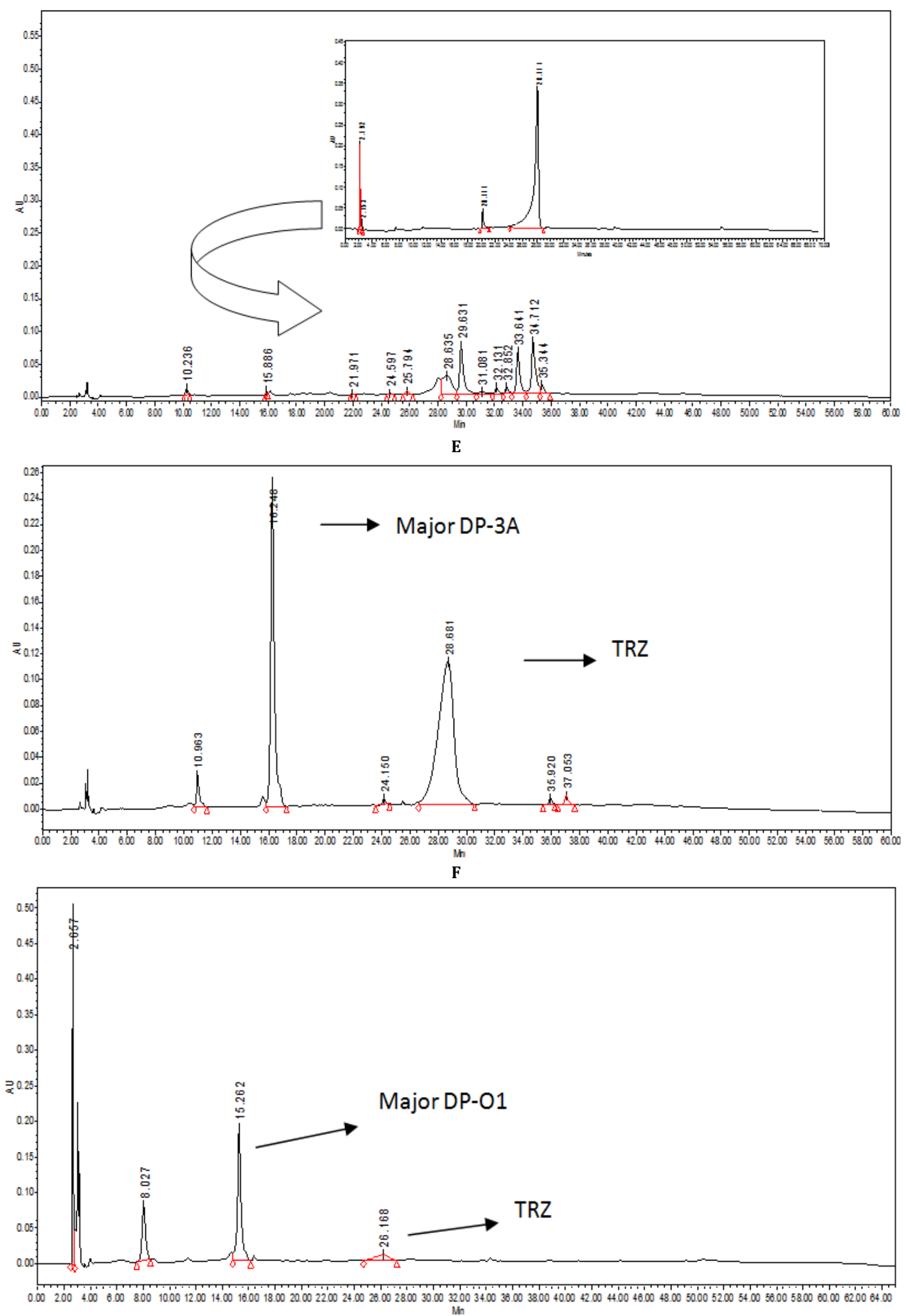

Fig. 2: HPLC Chromatogram for A) Specificity of Method B) Selectivity of method C) Acid degradation of TRZ D) Alkaline degradation of TRZ E) Water degraded TRZ F) Oxidation of TRZ

The DPs formed in these conditions were identified and major DPs were characterized using NMR and/or MS/MS. Peaks were evaluated against peak purity tests and \% area occupied in the chromatogram (\% Mass balance of 100) is shown in table 1. 
Table 1: Stress degradation report of TRZ by HPLC

\begin{tabular}{|c|c|c|c|}
\hline DPs and $R_{t}$ & Purity angle & Purity threshold & $\%$ Area \\
\hline \multicolumn{4}{|l|}{ (B)* TRZ bulk drug } \\
\hline **Peak: 20.11 & 0.168 & 0.565 & 5.30 \\
\hline API Peak-28.11 & 0.117 & 0.246 & 94.70 \\
\hline \multicolumn{4}{|c|}{ (C) ${ }^{*}$ TRZ acid degradation sample } \\
\hline Peak1: 8.1 & 1.415 & 0.281 & 4.25 \\
\hline Peak 2:15.3 & 0.133 & 0.248 & 46.79 \\
\hline \multicolumn{4}{|l|}{ (Major DP) } \\
\hline Peak 3:15.9 & 0.241 & 0.359 & 1.14 \\
\hline API: 26.4 & 0.211 & 0.303 & 44.86 \\
\hline \multicolumn{4}{|c|}{ (D)* TRZ neutral degradation sample } \\
\hline Peak1:10.9 & 0.241 & 0.373 & 2.40 \\
\hline Peak2: 16.2 & 0.104 & 0.241 & 32.99 \\
\hline \multicolumn{4}{|l|}{ (Major DP) } \\
\hline Peak3: 24.9 & 1.868 & 1.711 & 0.43 \\
\hline API: 26.6 & 0.188 & 0.274 & 62.85 \\
\hline Peak4: 35.9 & 1.155 & 1.300 & 0.48 \\
\hline Peak5: 37.0 & 0.310 & 0.947 & 0.84 \\
\hline \multicolumn{4}{|c|}{ (E)* TRZ alkali sample } \\
\hline API: 28.6 & 0.086 & 0.355 & 3.5 \\
\hline Peak1:29.6 & 0.063 & 0.245 & 5.5 \\
\hline Peak2:33.6 & 0.213 & 0.287 & 0.29 \\
\hline Peak3:34.7 & 0.257 & 0.267 & 7.89 \\
\hline Cluster of peaks & - & - & 82.82 \\
\hline \multicolumn{4}{|c|}{$(\mathrm{F})^{*}$ TRZ oxidative sample } \\
\hline Peak1: 8.027 & 1.945 & 1.115 & 19.11 \\
\hline Peak2: 15.262 & 0.237 & 0.248 & 46.85 \\
\hline \multicolumn{4}{|l|}{ (Major DP) } \\
\hline API: 26.168 & 0.244 & 0.248 & 7.42 \\
\hline $\mathrm{H}_{2} \mathrm{O}_{2}: 2.657$ & 1.177 & 3.919 & 26.62 \\
\hline
\end{tabular}

${ }^{*}$ Result for chromatograms shown in fig. $2^{* *}$ Process related impurity

\section{Validation of stability indicating method}

The stability-indicating method was validated as per ICH Q2 (R1) guidelines [9] in terms of linearity, range, precision and recovery. The good linearity was observed for the range $(50-300 \mu \mathrm{g} / \mathrm{ml})$ of TRZ with a correlation coefficient of 0.997. RSD (relative Standard deviation) for linearity, precision and recovery study was $<2.0 \%$ indicates that a precise and reproducible method was developed. The recovery for the study was in the range of 98.4-100.5\% indicates that good recovery was obtained. The assay result showed that $99.5 \%$ recovery of the formulation was observed. The validation results are shown in table 2 . The overlay of different concentrations of TRZ solution for linearity is shown in fig. 3 .

\section{Major degradation products}

The major degradation products were observed in acid, neutral and oxidative condition which was isolated for identification and characterization purpose.

\section{Confirmation of isolated DP}

The method for isolation of DP is described in the previous section. The isolated DPs were confirmed by HPLC and ESI/MS to check whether desired DP was isolated. The HPLC chromatogram and ESI/MS spectrum for isolated DPs of acidic, neutral and oxidized TRZ is shown in supplementary file S1.

\section{Characterization by NMR and/or tandem MS}

The characterization of isolated DP was done using NMR and/or Tandem MS to evaluate the structure of DP. Tandem MS spectrum and fragmentation pathway is shown in supplementary file S2 for acid, neutral and oxidative conditions.

The characterization for isolated DP was completed by NMR studies for acid $(4 \mathrm{H})$ and oxidative DP (01), ${ }^{1} \mathrm{H}$ NMR, for neutral DP-(3A), ${ }^{1} \mathrm{H},{ }^{13} \mathrm{C}$ and APT NMR (Supplementary file S3) was performed. The assignment of NMR spectrums is shown in table 3 for acid, neutral and oxidized DP.

Table 2: Validation of stability indicating method of TRZ

\begin{tabular}{ll}
\hline Parameters & Results \\
\hline Linearity & \\
Regression equation & $y=57453 \mathrm{x}+6 \mathrm{E}+06$ \\
Co-relation Coefficient & 0.997 \\
Range $(\mu \mathrm{g} / \mathrm{ml})$ & $50-300$ \\
RSD $(\%)$ & $<2.0 \%$ \\
Precision & 0.982 \\
Repeatability (\%RSD) & 0.920 \\
Intraday Precision (\%RSD) & 0.791 \\
Inter-day Precision (\% RSD) & \\
Recovery & $98.4-100.5$ \\
Recovery range (\%) & 4.23 \\
LOD $(\mu \mathrm{g} / \mathrm{ml})$ & 13.2 \\
LOQ $(\mu \mathrm{g} / \mathrm{ml})$ & \\
\hline
\end{tabular}




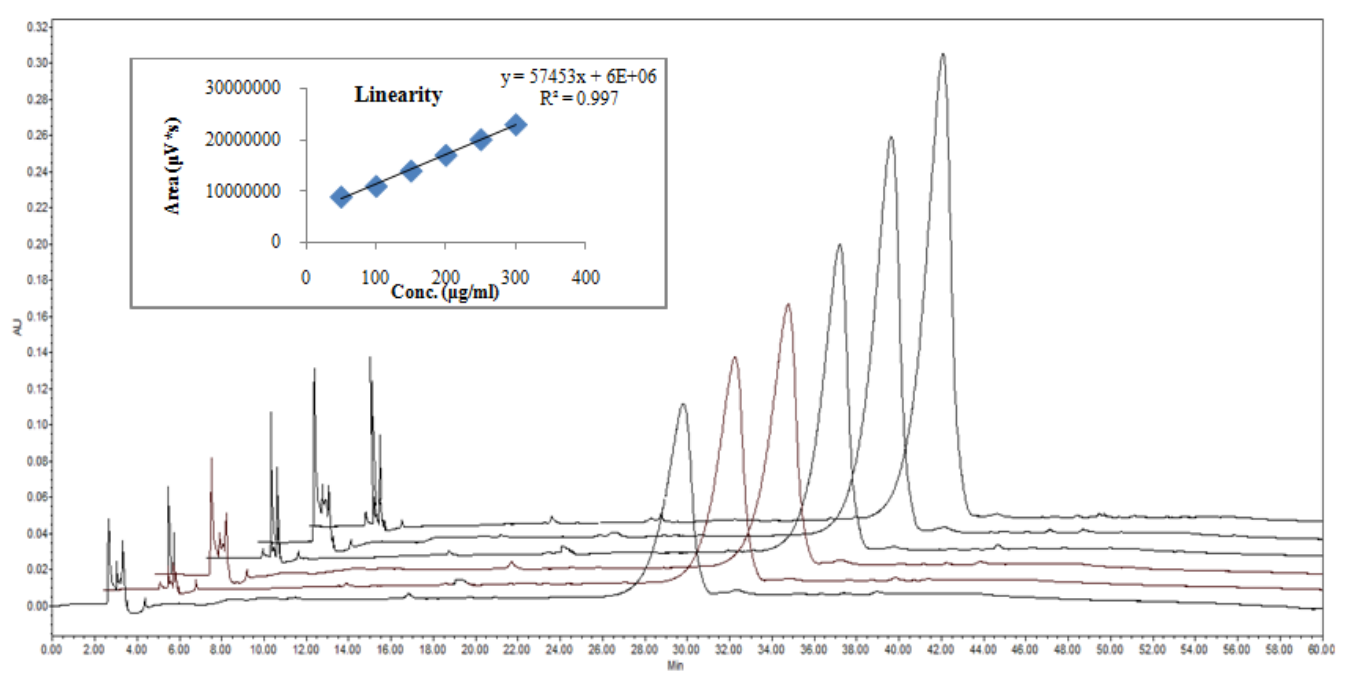

Fig. 3: Overlay chromatogram of TRZ and linearity plot

Table 3: NMR assignment for isolated major DP of oxide, acidic and neutral condition

\begin{tabular}{|c|c|c|c|c|c|c|}
\hline \multicolumn{7}{|c|}{ Chemical shift ( $\partial$, ppm) (Multiplicity) } \\
\hline$\alpha$-position & API & $\mathbf{0 1}$ & $4 \mathbf{H}$ & 3A & & \\
\hline & & ${ }^{1} \mathbf{H}$ & ${ }^{1} \mathbf{H}$ & ${ }^{1} \mathbf{H}$ & ${ }^{13} \mathrm{C}$ & APT \\
\hline 1 & $7.88(s)$ & $* 7.64(m)$ & $7.8(\mathrm{~m})$ & $7.6(s)$ & 128.0 & $-\mathrm{CH}(u f)$ \\
\hline 2 & $7.88(s)$ & $* 7.64(\mathrm{~m})$ & $7.6(m)$ & $7.6(s)$ & 128.0 & $-\mathrm{CH}(u f)$ \\
\hline 3 & $\mathrm{C}$ & - & $\mathrm{C}$ & $\mathrm{C}$ & 133.5 & $-\mathrm{C}(\mathrm{lf})$ \\
\hline 4 & $7.88(s)$ & $7.64(\mathrm{~m})$ & $7.8(m)$ & $7.8(s)$ & 128.0 & $-\mathrm{CH}(u f)$ \\
\hline 5 & $7.88(s)$ & - & $7.6(m)$ & $7.6(s)$ & 128.0 & $-\mathrm{CH}(u f)$ \\
\hline 6 & $\mathrm{C}$ & $* 4.26(\mathrm{brs})$ & $\mathrm{C}$ & $\mathrm{C}$ & 133.5 & $-\mathrm{C}($ lf $)$ \\
\hline 7 & $8.5(s)$ & $8.31(\mathrm{~m})$ & $8.4(s)$ & $8.4(s)$ & 150.4 & $-\mathrm{CH}(u f)$ \\
\hline 8 & $8.5(s)$ & $8.31(\mathrm{~m})$ & $8.4(s)$ & $8.4(s)$ & 150.4 & $-\mathrm{CH}(u f)$ \\
\hline 9 & $\mathrm{~N}$ & - & $\mathrm{N}$ & $\mathrm{N}$ & - & - \\
\hline 10 & $\mathrm{~N}$ & - & $\mathrm{N}$ & $\mathrm{N}$ & - & - \\
\hline 11 & $4.6(m)$ & $*_{-}$ & $4.3(\mathrm{~m})$ & $4.5(m)$ & 52.6 & $-\mathrm{CH}(u f)$ \\
\hline 12 & $4.6(m)$ & $*_{-}$ & $4.3(\mathrm{~m})$ & $4.5(m)$ & 52.6 & $-\mathrm{CH}(u f)$ \\
\hline 13 & $\mathrm{C}$ & $* 2.05(s)$ & - & - & 169.5 & $-\mathrm{C}(\mathrm{lf})$ \\
\hline 14 & 0 & *4.4 (brs) & *11.7(brs) & - & - & - \\
\hline 15 & $\mathrm{~N}$ & - & $* 10.0(\mathrm{~s})$ & $* 4.3(b r s)$ & - & - \\
\hline 16 & $4.4,4.5(t)$ & $* 4.4(\mathrm{brs})$ & $4.5(m)$ & $4.5(\mathrm{~m})$ & 39.3 & $-\mathrm{CH}(\mathrm{lf})$ \\
\hline 17 & $4.4,4.5(t)$ & *4.4 (brs) & $4.5(m)$ & $* 2.4(\mathrm{~m})$ & 39.3 & $-\mathrm{CH}(\mathrm{lf})$ \\
\hline 18 & $\mathrm{~N}$ & - & $* 1.5(s)$ & $* 4.3(\mathrm{brs})$ & - & - \\
\hline 19 & 0 & *7.7 (m) & - & - & - & - \\
\hline 20 & $\mathrm{C}$ & - & - & - & 159.5 & $-C(l f)$ \\
\hline 21 & 0 & - & - & - & - & - \\
\hline 22 & 0 & - & - & - & - & - \\
\hline 23 & - & - & - & - & 71.2 & $-2 \mathrm{CH}$ (lf) \\
\hline 24 & - & $11.60(s)(\mathrm{OH})$ & - & $* 4.4(\mathrm{~m})$ & 71.2 & $-2 \mathrm{CH}(\mathrm{lf})$ \\
\hline 25 & - & $11.60(s)(\mathrm{OH})$ & - & $* 4.3(s)$ & - & $\mathrm{OH}$ \\
\hline
\end{tabular}

Values with asterisk $(*)$ indicates changes observed in spectrum/l $f=$ Lower field $U p=$ Upper field in $\mathrm{C}^{13} \mathrm{NMR}$, the elucidated structures for DP are shown in fig. 4

\section{Impurity profiling}

The impurities were identified by $m / z$ ion of $[\mathrm{M}+\mathrm{H}]+$ of ESI-MS spectrum, high concentration sample was used to reduce $\mathrm{S} / \mathrm{N}$ (signal to noise) ratio and better signals. The reporting threshold for impurity is $0.5 \%$ (1000 mg daily dose- $<2 \mathrm{~g} /$ day dose) and the identification threshold is $1 \%$ of TRZ daily dose.

\section{Process related impurity}

The chromatogram of TRZ bulk drug showed process-related impurity which covered $5.30 \%$ of total area. The UPLC chromatogram and ESI/MS spectrum are shown in supplementary file S4. The ESI/MS spectrum of TRZ showed base peak of $391.5 \mathrm{~m} / \mathrm{Z}$ that indicates that adduct was formed with formate ion $[\mathrm{M}+\mathrm{Formic}$ acid $\left.(88)+\mathrm{H}^{+}\right]$. The $m / z$ for process-related impurity was $116.4 \mathrm{amu}$. The proposed structure for process-related impurity is shown in fig. 4 (E).

\section{Acid degradation products}

Degradation impurity identification by ESI/MS: The sample containing a mixture of DPs in acid solution was targeted for UPLCESI/MS to identify the minor DPs present in the sample along with major DP. The UPLC chromatogram and ESI/MS spectrum for peaks are shown in fig. 5. DPs are named as $1 \mathrm{H}$ to $7 \mathrm{H}$ where $\mathrm{H}$ stands for acid HCL. 


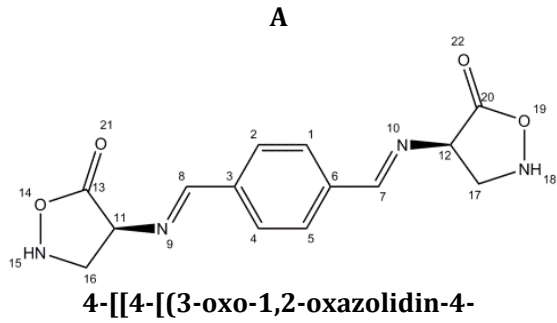

yl)iminomethyl]phenyl]methylideneamino]-1,2-oxazolidin-3-one C

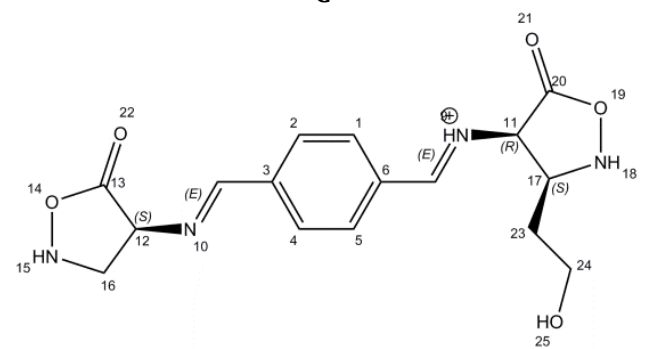

$(3 S, 4 R)-3-(-2-h y d r o x y e t h y l)-5-0 x o-N-((E)-4-((E)-(((S)-5-$ oxoisoxazolidin-4-yl)imino)methyl)benzylidene)isoxazolidin-4aminium

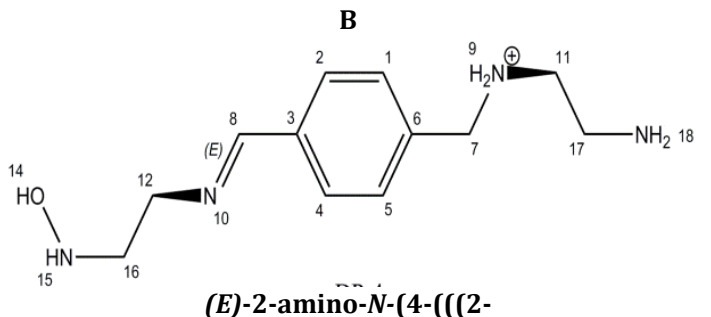

(hydroxyamino)ethyl)imino)methyl)benzyl)ethan-1-aminium D

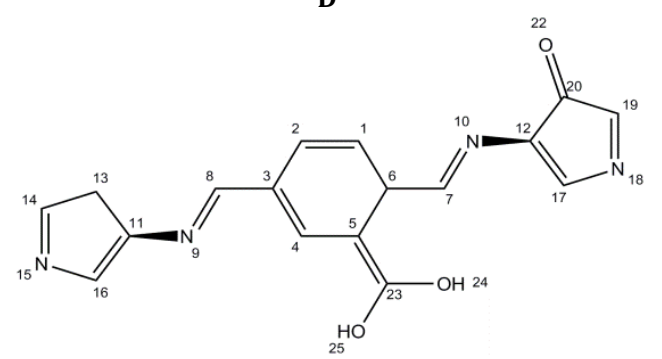

4-(( $(E)-(4-((E)-((3 H-p y r r o l-4-y l) i m i n o) m e t h y l)-6-$ (dihydroxymethylene)cyclohexa-2,4-dien-1-yl)methylene)amino)3 H-pyrrol-3-one

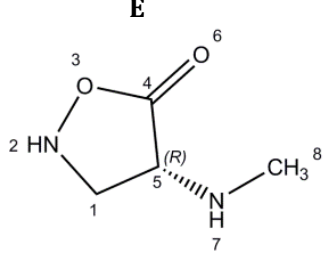

(R)-4-(methylamino) isoxazolidin-5-one

Fig. 4: Structure and name for A) TRZ API B) Acid-DP-4H C) water-DP-3A and D) oxidative condition-DP-O1 of TRZ E) Process related impurity
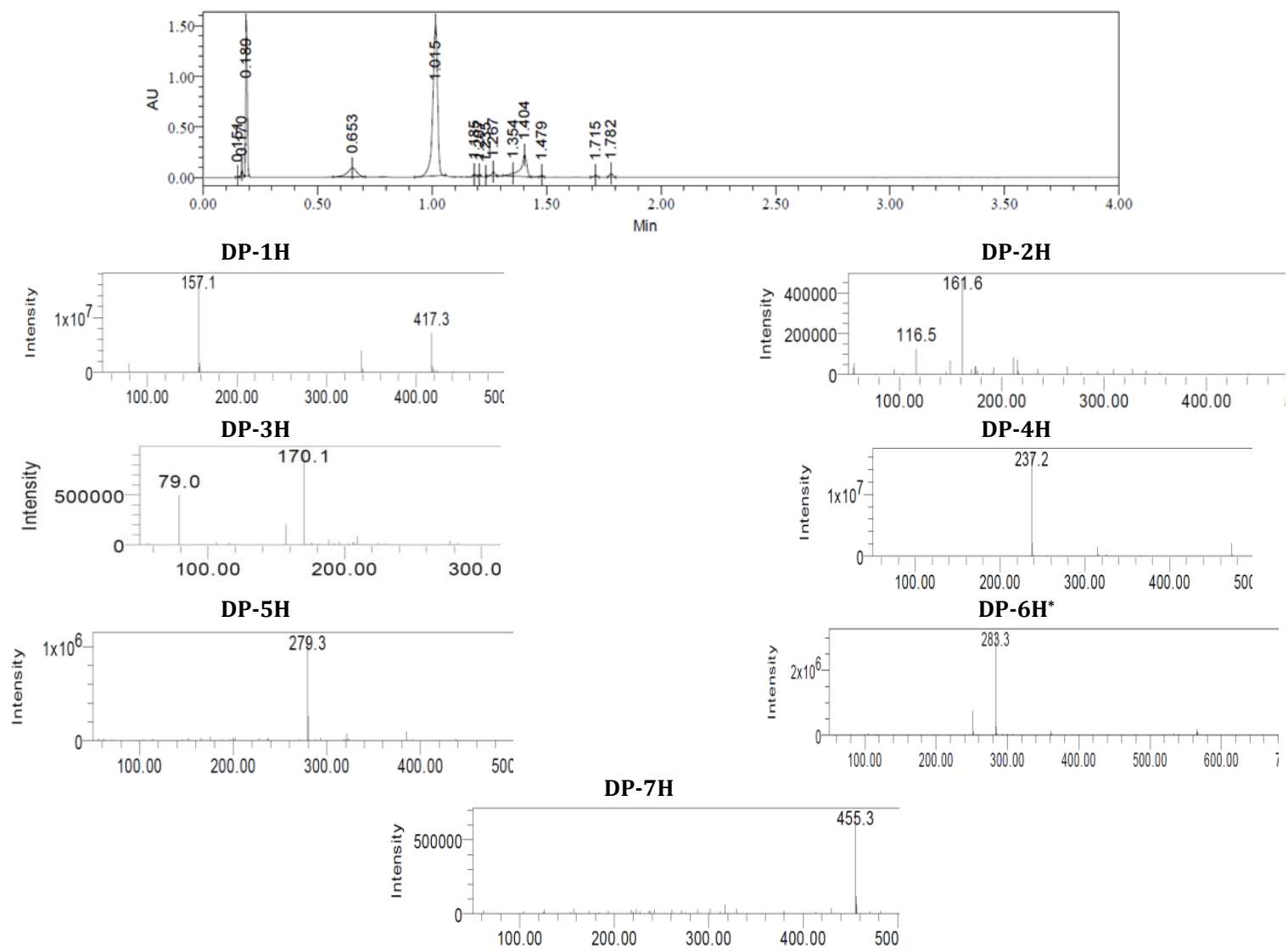

Fig. 5: UPLC chromatogram and ESI-MS spectrum for TRZ behavior in acid condition 
The peaks in fig. 5 are showing broadening and tailing, as high concentration sample was used for analysis to detect the very low responses in ESI/MS. The ESI-MS spectrum showed seven DPs, among which one was major DP $(4 \mathrm{H})$ and other DPs were eluted at Rt $0.198,0.669,0.981,1.204,1.2781 .495$ and 1.863 . The name of the DPs are mentioned in the increasing order of $m / z$ for DPs; DP-
$1 \mathrm{H}(\mathrm{m} / \mathrm{z} 417 \mathrm{Rt}, 0.198), \mathrm{DP}-2 \mathrm{H}(\mathrm{m} / \mathrm{z} 161$ co-elution with $\mathrm{m} / \mathrm{z} 116$ Impurity-1, Rt, 1.863), DP-3H(m/z $170 \mathrm{Rt}, 0.664), \mathrm{DP}-4 \mathrm{H}(\mathrm{m} / z$ 237.2,Rt,0.956,0.981, 1.029), DP $-5 \mathrm{H}(\mathrm{m} / z$ 279, Rt, 1.204), DP$6 \mathrm{H}(\mathrm{m} / \mathrm{z} 283, \mathrm{Rt}, 1.278)$ (reported in literature [8]) and $\mathrm{DP}-7 \mathrm{H}(\mathrm{m} / \mathrm{z}$ 455 , Rt, 1.495). The data is gathered in table 4 with the proposed structure.

Table 4: MS spectrum analysis and DP identification in acid medium

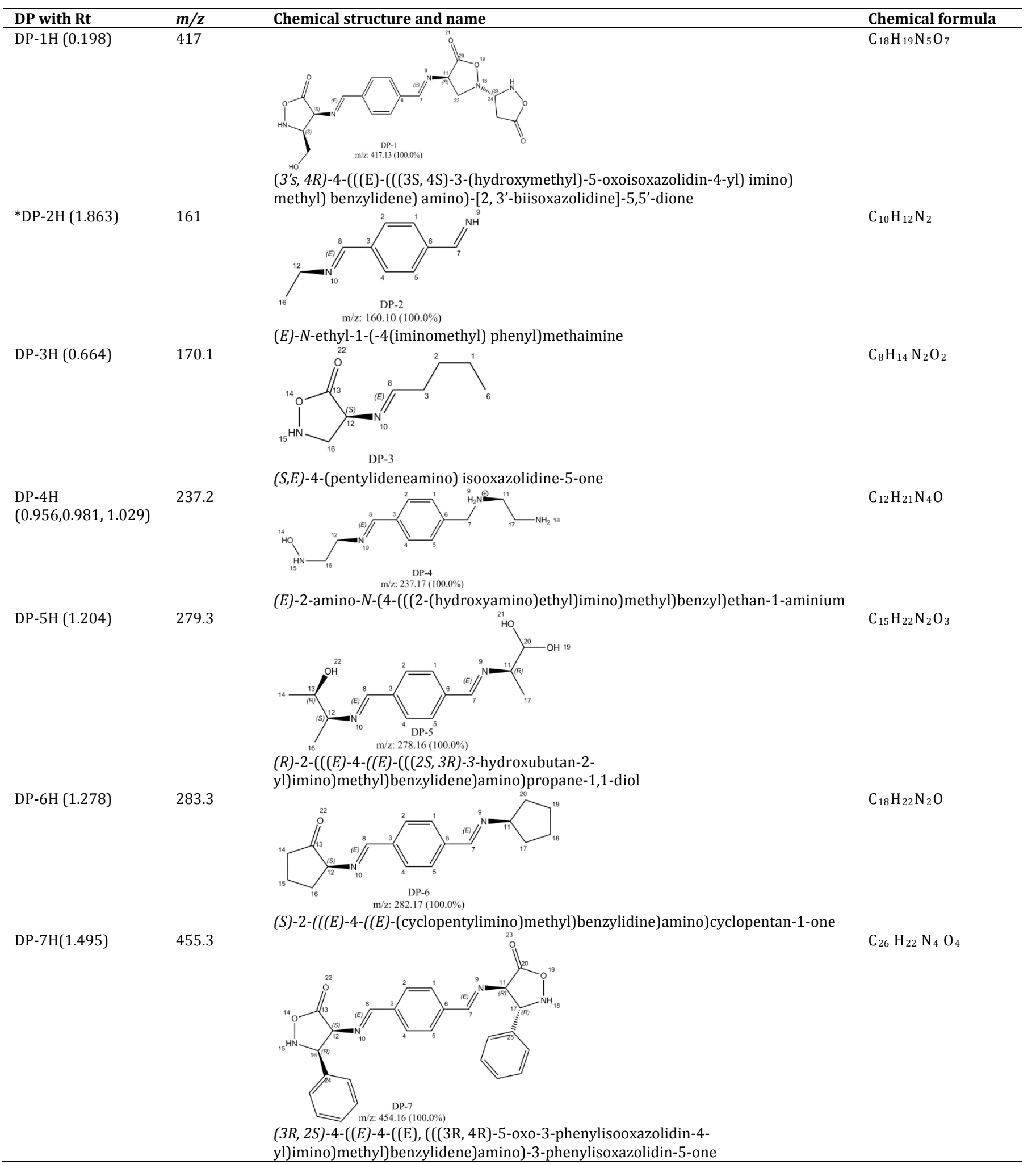

*reported in the literature [8], the possible mechanism for the formation of DP is discussed in the next section. The possible degradation pathway for TRZ in acid media is shown in fig. 6. 


\section{DP-1H}

The $m / z$ base value in DP-1H is 157.1, which is common background ion found in MS study that belongs to the DMSO $[2 \mathrm{M}+\mathrm{H}]+$ while DP- $1 \mathrm{~m} / \mathrm{z}$ is 417.3. The DP can be formed by conjugation between TRZ API and other Enantiomeric fragments of TRZ API with amine group of five-member ring while on another side- $\mathrm{O}-\mathrm{CH}_{2}$ group attached with amine group of the five-member ring. The attachment sight for TRZ is position $\mathrm{C}^{15 a n d 17}$ and $\mathrm{N}^{14 a n d 18}$. The DP-1 is formed due to addition of groups.

\section{DP-2H}

$\mathrm{DP}-2 \mathrm{H}$ is formed due to the degradation of a five-member ring attached to Enantiomeric carbon at $\alpha$-position 7 and 8. Another MS peak shown along with DP-2 is of process-related impurity, which is identified in previous section. The cleavage between position C-8 and $\mathrm{N}-10$ and between $\mathrm{N}-9$ and $\mathrm{C}-11$ formed $\mathrm{DP}-2 \mathrm{H}$.

\section{DP-3H}

The $m / z$ for DP-3H is 170.1 which suggest the degradation of benzene ring and five-member ring in TRZ structure. Another MS peak of 79 is because of solvent DMSO $[\mathrm{M}+\mathrm{H}]+$.

\section{DP-4H}

DP-4H is a major DP with $m / z$ of 237.0 ; identification and characterization is described in details in the previous section. The
$\mathrm{DP}-4 \mathrm{H}$ is formed due to the cleavage of five-member rings. Amine groups of five member ring remains attached while alcohol and ketone group is removed due to acid effect. The alcohol group remains attached to the amine in one of the side and it was confirmed by proton NMR spectrum analysis [11].

\section{DP-5H}

DP- $5 \mathrm{H}$ is formed due to the degradation of five-member ring, the alcohol group remains attached on both side and one more alcohol group remains attached to one of the side while other groups are removed due to acid-catalyzed reaction.

\section{${ }^{*}$ DP-6H}

The DP-6H is formed due to removal of alcohol and amine and ketone group from five-member rings of TRZ chemical structure. The ketone group in one of the side remains attached with fivemember ring. The DP is reported in the literature however, in this study DP-6H is minor DP.

\section{DP-7H}

The DP-7H is formed due to the attachment of benzene rings at attachment sites in TRZ chemical structure. The benzene ring is the fraction of TRZ chemical structure which is ruptured in acid media.

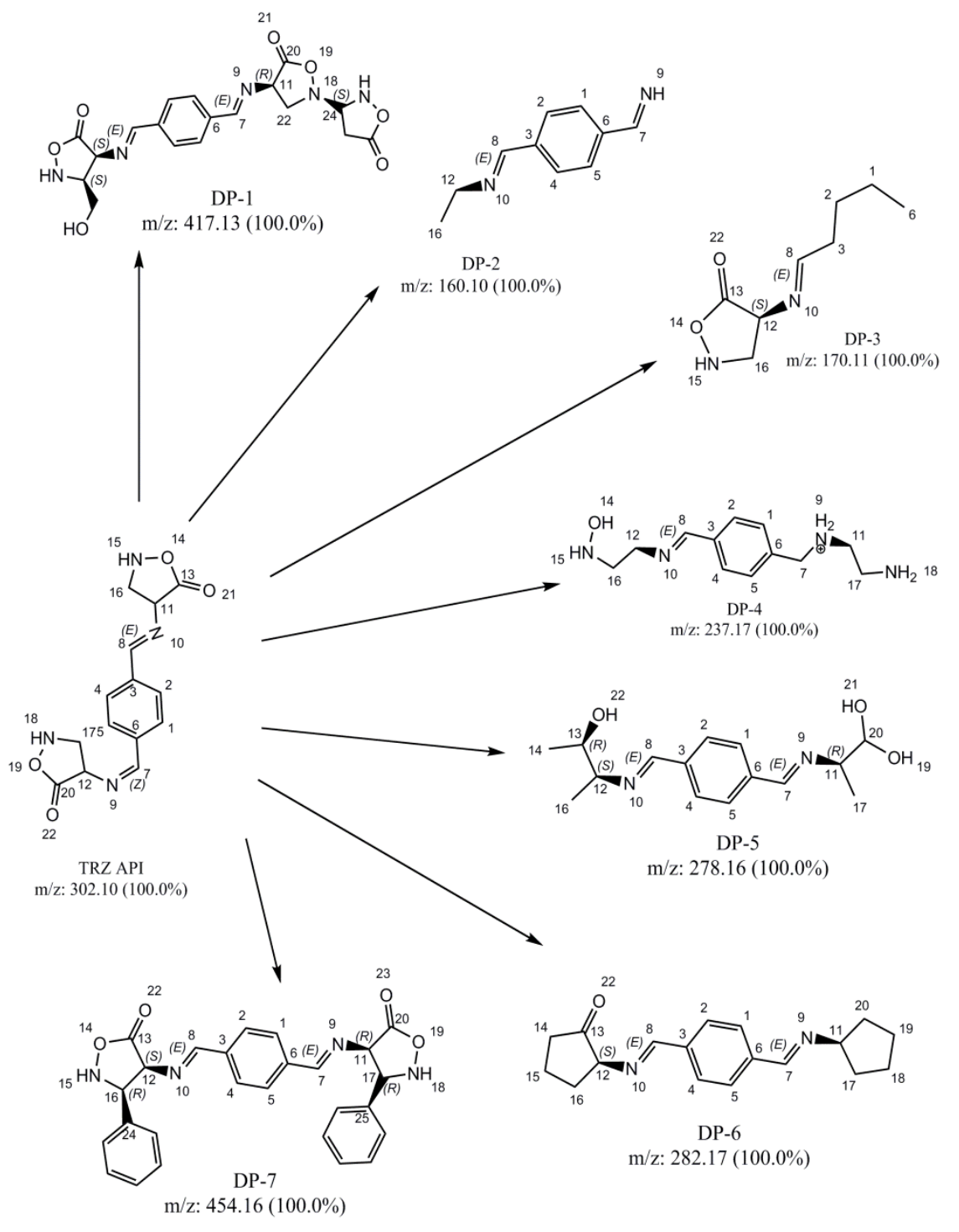

Fig. 6: Degradation pathway of TRZ in acid media 


\section{Alkaline degradation products}

Several fractions were formed in alkaline condition after degradation of TRZ and ESI/MS spectrum showed several peaks for fractions. It was not possible to report all of them and there was no intense or major peak that can be considered as major or reportable. The pattern for degradation of TRZ in alkaline condition was in $0.5 \mathrm{~N}$ $\mathrm{NaOH}$ at RT, TRZ peak appeared for 35 min after 35 min the fractions shown in fig. 2 were observed, for lower concentration the degradation time point was extended but the same chromatogram was obtained.

\section{Aqueous degradation products}

The TRZ bulk drug was degraded in water at RT in the dark and it formed five new peaks in TRZ HPLC chromatogram among which one major DP was formed at Rt16.02 min while one DP was formed at Rt 24.02 min showed co-elution of substance with it. The DPs formed in neutral degradation study was less than the identification and reporting threshold except for DP-1A and DP-2A. For that reason in UPLC-ESI/MS spectrum, the data shown the mass peak without coelution was identified and other mass clusters were reported.

Degradation impurity identification by ESI/MS: The UPLC chromatogram for TRZ neutrally degraded sample is shown in fig. 7 with mass peaks.

The peak at Rt $0.697,0.905$ and 0.988 were single eluted peaks therefore identified. DP at 0.988 was a major DP. The clusters of mass peaks are reported in the degradation pathway. The analysis of the mass spectrum is shown in table 5. The DPs are named as DP-1A to $3 \mathrm{~A}$ where $\mathrm{A}$ stands for aqueous condition.
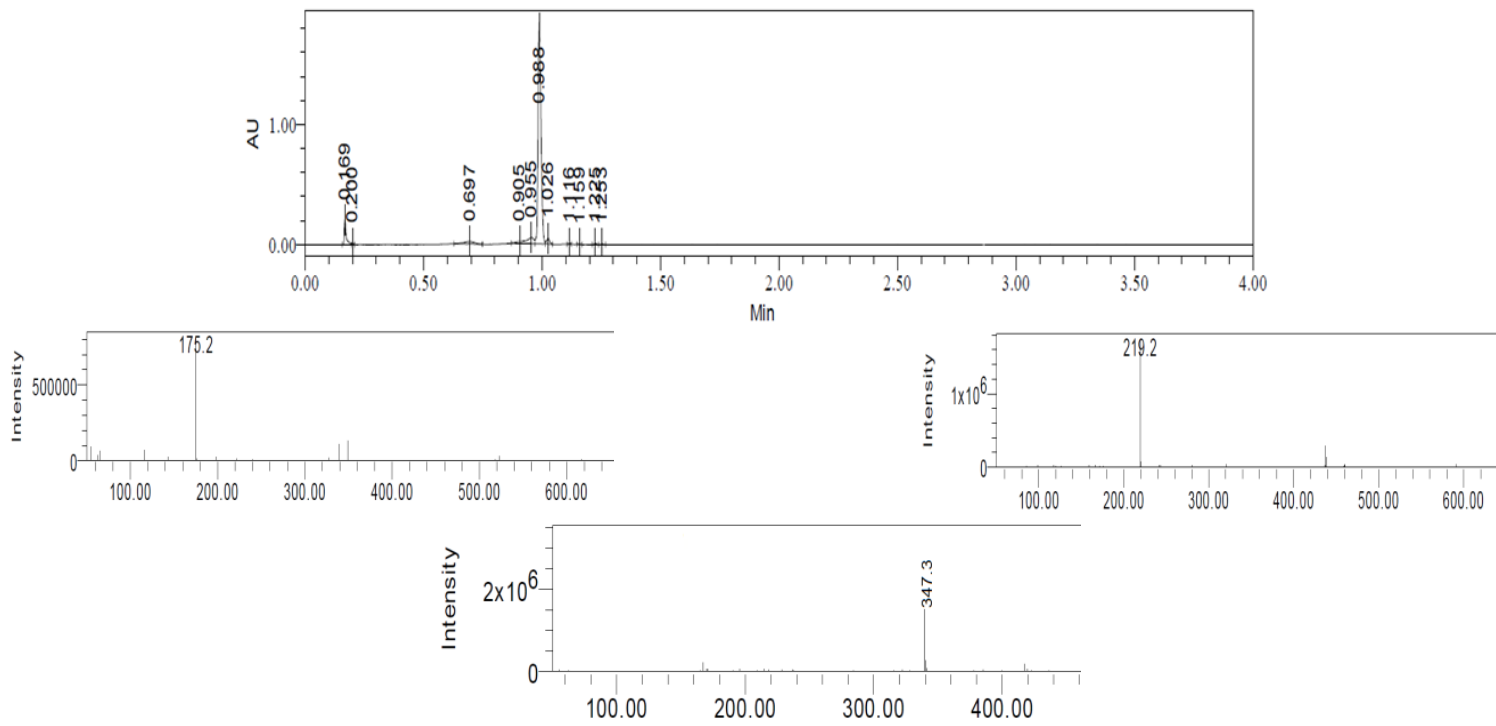

Fig. 7: UPLC chromatogram and ESI-MS spectra for TRZ behavior in neutral media

Table 5: Mass spectrum analysis of TRZ in neutral media

\begin{tabular}{lll}
\hline DP and Rt & Chemical formula \\
\hline $\mathrm{DP}-1 \mathrm{~A}$ & $\mathbf{m} / \mathbf{z}$ & $\mathrm{C}_{12} \mathrm{H}_{17} \mathrm{~N}$ \\
$(0.905)$ & 175.2 \\
$\mathrm{DP}-2 \mathrm{~A}$ \\
$0.697)$
\end{tabular}

Three DPs those were single eluted, identified for neutral degradation of TRZ. The $m / z$ of clusters is reported in the proposed degradation pathway and mechanisms for the formation of DPs are described below; the proposed degradation pathway is shown in fig. 8. 


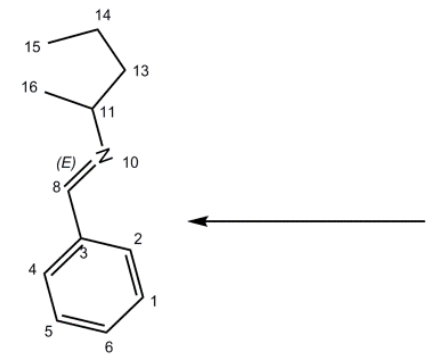

DP-1 $\mathrm{m} / \mathrm{z}: 175.14(100.0 \%)$

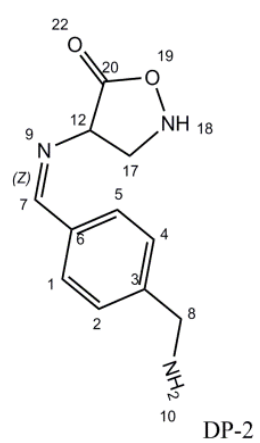

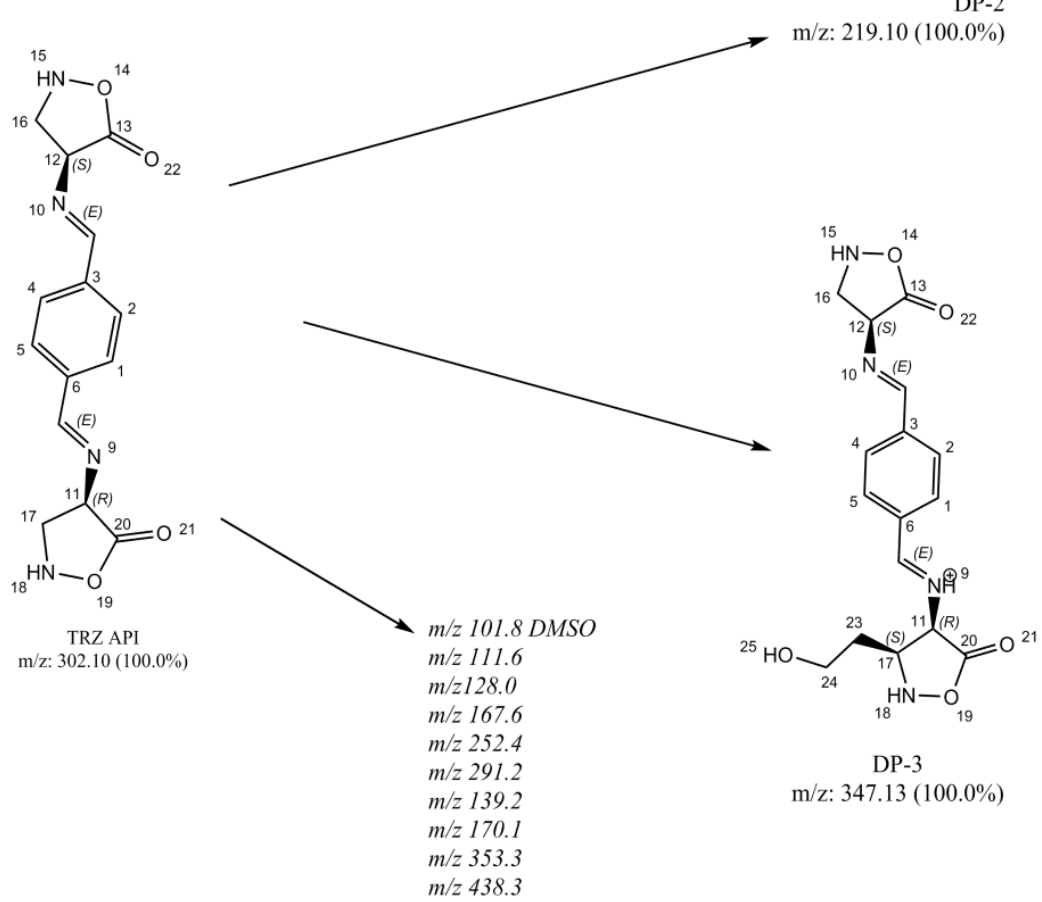

Fig. 8: Proposed degradation pathway for TRZ in neutral media

\section{DP-1A}

The DP- $1 \mathrm{~A}$ is formed due to the removal of a five-member ring from side $\mathrm{A}$ and on another side (B) removal of ketone $(=0)$, alcohol $(-0)$ and amine $\left(-\mathrm{NH}_{2}\right)$ group. The hydrolysis of TRZ formed DP-1A from the source DP-2A.

\section{DP-2A}

The DP-2A showed $m / z$ 219, which suggest the removal of fivemember ring attached to amine group. The cleavage of bond between amine $(-\mathrm{NH})$ and carbon of five-member ring formed the DP-2A. The hydrolysis of TRZ was the mechanism for formation of DP-2A

\section{DP-3A}

The attachment of the methoxy group at position C-17 resulted in the formation of DP-3A (major DP). TRZ was not stable in proteolytic solution and formed a number of DPs. The attachment may be result of constant conformational change, which stabilized in the form of DP-3A.

\section{Oxidized degradation products}

TRZ was kept in the presence of oxidative agent to notice any change in TRZ chemical structure by observing the change in HPLC chromatogram. The chromatogram showed two additional peaks other than TRZ and hydrogen peroxide peak. Major peak-2 was passed in purity test and was isolated by preparative HPLC, identified by ESI/MS and Tandem MS, characterized by proton NMR. The co-eluting substances in peak-1 were identified by ESI/MS.

Degradation impurity identification by ESI/MS: Identification of DP was carried out by ESI/MS. The UPLC chromatogram and ESI/MS spectrum is shown in supplementary file S5. The UPLC chromatogram showed 11 mass peaks among which one was major DP which has $m / z$ 323.3. The ten DPs were eluted in HPLC chromatogram at Rt $8.027 \mathrm{~min}$. The DPs with $\mathrm{m} / z 170$ (3H), 417 $(1 \mathrm{H})$ and $237(4 \mathrm{H})$ are already identified in acid medium while other DPs are not identified as the mass peaks appeared as cluster with low percentage of area covered by peaks.

The major DP with $m / z 323.1$ suggests the oxidation of TRZ. The oxidation in presence of oxidizing agent was occurred at position 22 and 17 in TRZ chemical structure. The conjugation or/and fragmentation of TRZ formed other minor DPs. The Oxide DP (01) is named as (4S, 5S)-5-hydroperoxy- $N$ - $((E)-4-((\mathrm{E})-(((\mathrm{R})-5$-oxo-1,3,2dioxazolidin-4-yl)imino)methyl)benzylidine)isoxazolidin-4-aminium that matches with chemical formula $\mathrm{C}_{13} \mathrm{H}_{15} \mathrm{~N}_{4} \mathrm{O}_{6}$.

The proposed degradation pathway is shown in fig. 9. 

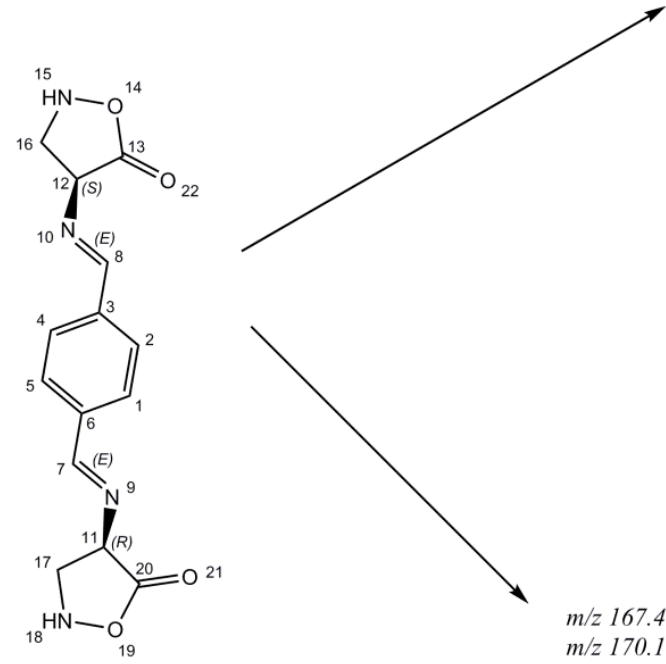

TRZ AP m/z: $302.10(100.0 \%)$

$\mathrm{m} / \mathrm{z} 167.4$ $\mathrm{m} / \mathrm{z} 170.1$ $\mathrm{m} / \mathrm{z} 237.2$ $\mathrm{m} / \mathrm{z} 285.2$

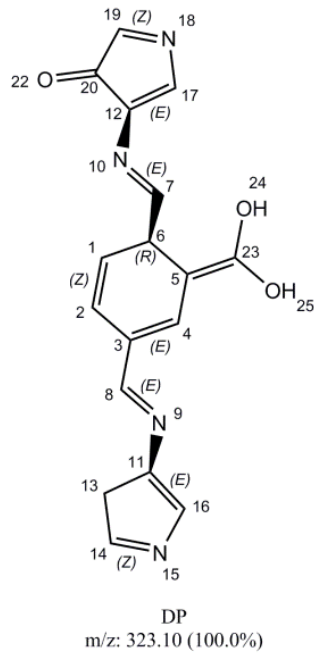
$m / z 291.2$ $\mathrm{m} / \mathrm{z} 307.6$ $\mathrm{m} / \mathrm{z} 326.2$ $\mathrm{m} / \mathrm{z} 339.2$ $\mathrm{m} / \mathrm{z} 351.3$ $m / z 417.3$

Solvent peak $m / z 79$ [DMSO] $\mathrm{m} / \mathrm{z} 157$ [DMSO]

Fig. 9: Proposed degradation pathway for TRZ in oxidative media

\section{DISCUSSION}

The analytical method developed for stability study was accurate, precise and sensitive enough to detect low concentration of impurity in TRZ sample. The validation of method was successfully completed applying ICH Q2 (R1) guideline, which suggest the RSD value $<2.0 \%$ for linearity, precision and accuracy study.

The stress degradation study revealed that TRZ was liable to degradation in hydrolytic solutions and in presence of oxidative agent while TRZ was chemically stable in thermal condition and under UV light for more than $21 \mathrm{~d}$, although color change from white to pale yellow was visualized without chemical change in TRZ. Process-related impurity or inherent impurities may be present in API due to incomplete reaction during synthesis or the by-product of synthesis reaction of bulk drug. This impurity may or maybe not take part in chemical reaction of bulk drug. During synthesis of TRZ bulk drug, cleavage between Enantiomeric carbon $\left(\mathrm{C}^{7}\right)$ and benzene ring carbon $\left(\mathrm{c}^{6}\right)$ resulted in incomplete reaction and formed Impurity-1 (process-related impurity). The $m / z$ of impurity- 1 obtained by UPLC/ESI-MS was $116 \mathrm{amu}$ which is matching with the chemical formula $\mathrm{C}_{4} \mathrm{H}_{8} \mathrm{~N}_{2} \mathrm{O}_{2}$. [10]In acid media,for degradation of TRZ, acidic environment was liable, which resulted in formation of 7 DPs $(1 \mathrm{H}-7 \mathrm{H})$. The DPs were result of the cleavage of bonds where acid was appearing as catalyst. The major DP-4H was the result of hydrolysis in the presence of acid. If TRZ is not treated for a longer duration in acid (such as gastric acid in the human body), degradation products will start to form that might be biologically active, have toxic or adverse effects. Therefore it is recommended to coat TRZ formulation with a suitable agent or to improve the solubility of TRZ in water. In neutral media (water), TRZ bulk drug undergone hydrolysis and methylation to form 10 DPs (1A-10A) among which three DPs were noticeable (1A-3A). TRZ is highly reactive in aqueous solutions; therefore, it is recommended to form a stable salt of TRZ to avoid the degradation of TRZ in water. The oxidative agent reacts with TRZ to form a degradation product of oxidation reaction. It is recommended to avoid any oxidizing agent during the production of formulation or during the course of storage of TRZ bulk drug or formulation. TRZ is highly susceptible for alkaline medium. The study suggests taking high precautions during formulation production as well as in the storage of bulk drug and formulation to avoid unwanted reaction or degradation of TRZ.

\section{CONCLUSION}

The stability study for TRZ was performed and it was observed that TRZ degraded in acid, neutral, alkaline and oxidative medium while stable under UV and thermal conditions. TRZ was highly sensitive for alkaline media. The major DPs were isolated, identified and characterized using different sophisticated instruments. While minor DPs present in sufficient quantity to fall in the category of classification of identification of impurity was identified using ESI/MS spectrum. The process-related impurity and other degradation impurities are reported for the first time. The study results are handy material for suggested storage conditions and improvement in formulation development.

\section{ACKNOWLEDGEMENT}

Authors would like to acknowledge Shree G. H Patel, center for relevance and NDDS for providing facilities to carry out the practical work and Macleods Pharmaceuticals for providing gift sample.

\section{FUNDING}

\section{Nil}

\section{AUTHORS CONTRIBUTIONS}

SJR developed the concept of the study, designed the study and guided and supervised the study. The first draft of manuscript was proof read by SJR and suggested suitable corrections. PJV designed 
the study, conducted the literature survey, performed the practical, collected, and analyzed and interpreted the data. PJV Wrote the first draft of manuscript. All the authors approve the final draft of manuscript.

\section{CONFLICT OF INTERESTS}

The Authors have declared no conflict of interest

\section{REFERENCES}

1. Internet, Centers for disease control and prevention, World TB day; 2020. Available from: https://www.cdc.gov/tb/ worldtbday/history.htm\#: :text=0n\%20March $\% 2024 \% 2 \mathrm{C} \% 2$ 01882\%2C\%20Dr,the\%20United\%20States\%20and\%20Euro pe. [Last accessed on 30 Jan 2018]

2. Internet, Information about Tuberculosis, TB Facts. Available from. https://tbfacts.org/deaths-from-tb/. [Last accessed on 20 Dec 2020].

3. Internet, Central Drugs Standard Control Organization (CDSCO), Home/Drugs. Available from: https://cdscoonline.gov.in/ CDSC0/Drugs. [Last accessed on 09 Jan 2018].

4. Khairnar SK, Nagras MA, Sonawane AM. Development and validation of UV spectrophotometric method for the estimation of terizidone in bulk and pharmaceutical dosage form. Inventi Rapid: Pharm Anal Quality Assurance 2016;3:1-4.

5. Mulubwa M, Mugabo P. Analysis of terizidone in plasma using HPLC-UV method and its application in a pharmacokinetic study of patients with drug-resistant tuberculosis. Biomed Chromatogr 2018;32:4325-50.

6. Gandhi SV, Shevale VP, Choudhari GB. Development and validation of a stability-indicating rp-hplc method for the determination of terizidone. Indo Am J Pharm 2018;5:1353-61.

7. Bhole RP, Phadke SP. Development and validation of HPTLC and LC/MS/MS method for estimation of terizidone in pharmaceutical dosage. TJPS 2019;42;196-202.

8. Patil PP. Alalaiwe A. Two new degradation products of terizidone: an application of forced degradation study and hyphenated chromatographic techniques, Int J Pharma BioSci 2019;10:58-70.

9. Internet, ICH Quality guidelines. Available from: https://www.ich.org/page/quality-guidelines [Last accessed on 20 Dec 2020].

10. Akshtha HS, Gurupadyya BM. Application of liquid chromatography coupled with mass spectrometry in the impurity profiling of drug substances and products. Asian J Pharm Clin Res 2018;11:30-7.

11. Berkenov K, Datkhayev UM. Preparation and analysis of the nmr spectra of the pharmaceutical substanceâ«oose11,12,13â». Asian J Pharm Clin Res 2017;10:292-6. 